\title{
From a lost world: an integrative phylogenetic analysis of $A$ Ansonia Stoliczka, 1870 (Lissamphibia: Anura: Bufonidae), with the description of a new species
}

\author{
Lea E. Waser ${ }^{1,2}$ - Manuel Schweizer ${ }^{1,2}$ - Alexander Haas ${ }^{3} \cdot$ Indraneil Das $^{4}$. \\ André Jankowski ${ }^{3} \cdot$ Pui Yong Min $^{4} \cdot$ Stefan T. Hertwig ${ }^{1,2}$
}

Received: 18 December 2015 / Accepted: 30 June 2016

(C) Gesellschaft für Biologische Systematik 2016

\begin{abstract}
While the island of Borneo is considered a global biodiversity hotspot, the species richness in many groups remains unknown and appears underestimated. During herpetological surveys carried out in the interior of Sarawak, East Malaysia, several individuals of a small species of the genus Ansonia Stoliczka 1870 were collected on the Usun Apau plateau and in the Gunung Hose mountain range (Ansonia sp. Usun Apau). An integrative taxonomic approach comprising phylogenetic $(2.4 \mathrm{~kb}$ mitochondrial rDNA fragment, Bayesian Inference and Maximum Likelihood, $>5.1 \%$ to its closest relative) and morphometric analyses (25 measurements, multivariate ratio analysis and linear discriminant analysis), as well as morphological comparisons support the status of this operational taxonomic unit as a separate taxon at species level. The obtained phylogenetic hypothesis corroborates
\end{abstract}

Electronic supplementary material The online version of this article (doi:10.1007/s13127-016-0294-2) contains supplementary material, which is available to authorized users.

Stefan T. Hertwig

stefan.hertwig@nmbe.ch

Alexander Haas

alexander.haas@uni-hamburg.de

Indraneil Das

idas@ibec.unimas.my

1 Naturhistorisches Museum der Burgergemeinde Bern, Bernastrasse 15, CH-3005 Bern, Switzerland

2 Institute of Ecology and Evolution, University of Bern, Baltzerstrasse 6, CH-3012 Bern, Switzerland

3 Biozentrum Grindel und Zoologisches Museum Hamburg, Martin-Luther-King-Platz 3, 20146 Hamburg, Germany

4 Institute of Biodiversity and Environmental Conservation, Universiti Malaysia Sarawak, 94300 Kota Samarahan, Sarawak, Malaysia the two major clades within Ansonia found in previous studies. Within Clade One Ansonia sp. Usun Apau and the enigmatic Ansonia torrentis are part of a monophyletic group of the Bornean species Ansonia hanitschi, Ansonia minuta, Ansonia platysoma, Ansonia spinulifer, Ansonia vidua, and two additional undescribed taxa. This subclade must be considered as the result of an on-island radiation in the complex evolution of Ansonia. The new species is formally described including the identification of diagnostic morphometric traits. Ansonia sp. Usun Apau is endemic to two isolated mountain ridges in central Sarawak and must be considered as a new element of the unique diversity of the Bornean amphibian fauna that is potentially threatened by habitat loss at least in parts of its range.

Keywords Ansonia teneritas $\cdot$ New species $\cdot$ Integrative taxonomy $\cdot$ Phylogeny $\cdot$ Diversity $\cdot$ Evolution . Morphometrics · Usun Apau · Borneo · Mitochondrial DNA

\section{Introduction}

The Usun Apau plateau is one of the last inaccessible and uninhabited areas of Sarawak, Borneo, in East Malaysia. A volcanic plateau located at the headwaters of the Baram and Rajang rivers near the Indonesian border, it is protected today as a national park but was unknown to western science until 1951, when Tom Harrisson, the curator of the Sarawak Museum in Kuching, visited the site (Arnold 1957). During our herpetological expedition to the Usun Apau National Park in 2010, a series of individuals of a small species of the genus Ansonia Stoliczka 1870 was collected (Fig. 1). These were initially regarded during field work as conspecific with either Ansonia hanitschi, Ansonia minuta, or Ansonia platysoma due to their small size and overall similarity in external morphology. Subsequent 